\title{
Concise Commentary: Significance of Rapid Gastric Emptying in Dyspepsia_Is the Stomach 30\% Empty or 30\% Full?
}

\author{
Aashesh N. Verma ${ }^{1}$. Ali Rezaie ${ }^{2}$ \\ Published online: 20 August 2019 \\ ○) Springer Science+Business Media, LLC, part of Springer Nature 2019
}

Rapid gastric emptying (RGE), defined as $<30 \%$ retention at the one hour mark of a gastric emptying study (GES), has classically been associated with conditions such as dumping syndrome or seen after surgery for peptic ulcer disease [1]. While RGE is an accepted entity, its clinical significance has been questioned, since gastric emptying and symptoms are poorly correlated [2], although more recent studies have suggested that in some patients, functional dyspepsia symptoms correlate with RGE [3].

In this issue of Digestive Diseases and Sciences, Cifuentes et al. determined the clinical predictors of RGE in symptomatic patients, with the purpose of defining a distinct population more likely to develop RGE [4]. The authors retrospectively analyzed characteristics of patients with RGE, correlating them with dyspeptic symptoms in comparison with symptomatic patients with normal gastric emptying. Older, male smokers with higher BMI were more likely to have RGE. Patients with RGE were more likely to have symptoms of nausea/vomiting, weight loss, and autonomic symptoms when compared with those with NGE although no correlation with measurable autonomic dysfunction was found. Diabetes was the most common comorbidity associated with RGE, and a history of fundoplication was a strong predictor of RGE among non-diabetics.

The study included a large cohort of subjects, 2904, of which 9\% had RGE. Their findings suggest that there is a distinct population of symptomatic patients who can be identified when assessing for gastroparesis, who in fact have RGE. Identification of these patients is clinically significant, as they may not respond favorably to prokinetic agents, a standard therapy for DGE. Ultimately, identification of symptomatic patients with RGE could change clinical practice to a therapeutic strategy customized to their unique physiology, for which buspirone has been identified as a potential therapeutic agent [5]. Further studies are needed to assess the clinical response to tailored therapy for patients with RGE and to assess the optimal cutoff for percentage of retention at $1 \mathrm{~h}$ in order to refine the definition of RGE.

\section{References}

1. Abell TL, Camilleri M, Donohoe K, et al. Consensus recommendations for gastric emptying scintigraphy: a joint report of the American Neurogastroenterology and Motility Society and the Society of Nuclear Medicine. Am J Gastroenterol. 2008;103:753-763.

2. Balan K, Sonoda LI, Seshadri N, Solanki C, Middleton S. Clinical significance of scintigraphic rapid gastric emptying. Nucl Med Commun. 2011;32:1185-1189.

3. Kusano M, Zai H, Shimoyama Y, et al. Rapid gastric emptying, rather than delayed gastric emptying, might provoke functional dyspepsia. J Gastroenterol Hepatol. 2011;26:75-78.

4. Cifuentes J, Radetic M, Lopez R, Gabbard S. Clinical predictors of rapid gastric emptying in patients presenting with dyspeptic symptoms. Dig Dis Sci. (Epub ahead of print). https://doi. org/10.1007/s10620-019-05620-8.

5. Tack J, Janssen P, Masaoka T, Farré R, Van Oudenhove L. Efficacy of buspirone, a fundus relaxing drug, in patients with functional dyspepsia. Clin Gastroenterol Hepatol. 2012;10:1239-1245.

Publisher's Note Springer Nature remains neutral with regard to jurisdictional claims in published maps and institutional affiliations.

Ali Rezaie

Ali.Rezaie@cshs.org

1 Department of Gastroenterology, Rush University Medical Center, Chicago, IL, USA

2 GI Motility, Cedars-Sinai Medical Center, Los Angeles, CA, USA 